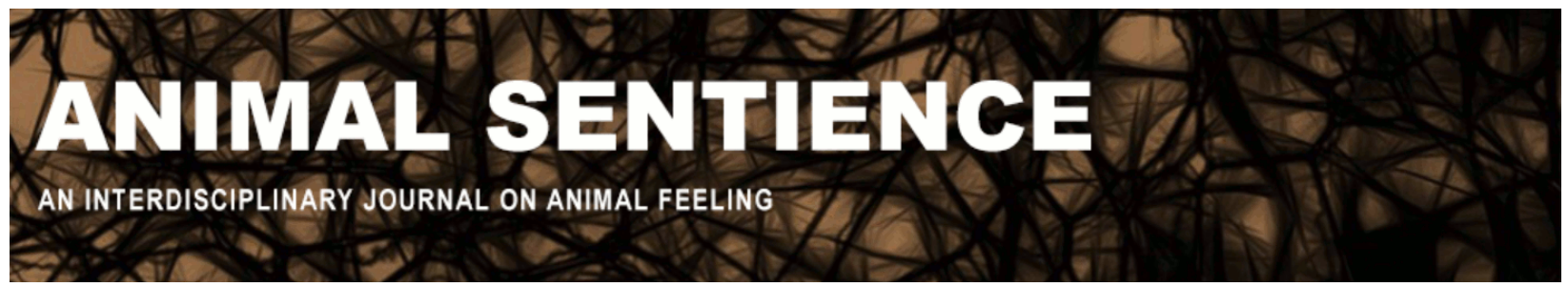

Velmans, Max (2016) How could consciousness emerge from adaptive functioning?. Animal Sentience 11(6)

DOI: $10.51291 / 2377-7478.1160$

Date of submission: 2016-09-05

Date of acceptance: 2016-09-12 (c) 


\title{
How could consciousness emerge from adaptive functioning?
}

Commentary on Reber on Origins of Mind

\author{
Max Velmans \\ Department of Psychology \\ Goldsmiths, University of London
}

\begin{abstract}
The sudden appearance of consciousness that Reber posits in creatures with flexible cell walls and motility rather than non-flexible cells walls and no motility involves an evolutionary discontinuity. This kind of "miracle" is required by all "discontinuity" theories of consciousness. To avoid miraculous emergence, one may need to consider continuity theories, which accept that different forms of consciousness and material functioning coevolve but assume the existence of consciousness to be primal in the way that matter and energy are assumed to be primal in physics.
\end{abstract}

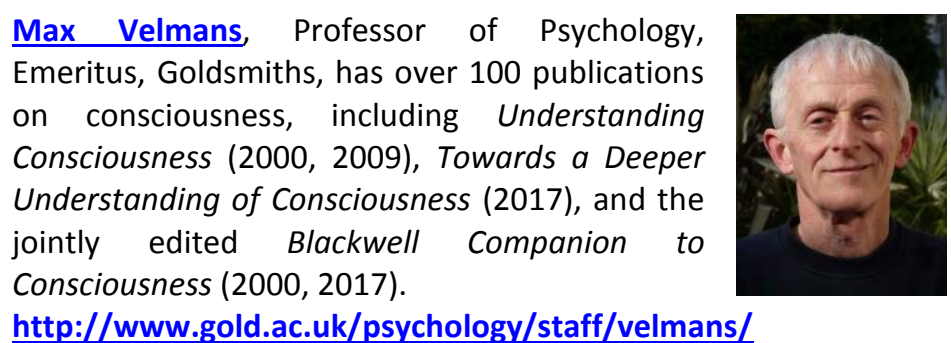

Where should one draw the line between entities that are conscious and those that are not? In my various surveys of research on this question (Velmans, 2000, ch. 12; 2007; 2009, ch. 14; 2011, 2012), I conclude that theories about the distribution of consciousness divide into continuity and discontinuity theories. Continuity theorists suggest that there is no arbitrary line in the descent from macroscopic to microscopic matter at which consciousness suddenly appears out of nothing. Rather, elementary forms of matter may be associated with elementary forms of experience. And if they encode information, they may be associated with rudimentary forms of mind. Discontinuity theories all claim that consciousness emerged at a particular point in the evolution of the universe. They merely disagree about which point. Consequently, discontinuity theories all face the same problem. What switched the lights on? What is it about matter, at a particular stage of evolution, that suddenly gave it consciousness? Nearly all try to define the point of transition in functional terms, although they disagree about the nature of the critical function. Some think consciousness "switched on" only in humans, for example, once they acquired language or a theory of mind. Some believe that consciousness emerged once brains reached a critical size or complexity. Others believe it co-emerged with the ability to learn, to move, or to respond in some other adaptive way to the environment.

Given the unquestionable presence of consciousness in humans and its likely presence in many other animals, it is entirely reasonable for Reber (2016) to search for the origins of consciousness in early forms of organic life and to link the evolution of consciousness to the evolution of those organisms. As he asserts in the Axiom on which his Cellular Basis of 
Consciousness ( $\mathrm{CBC}$ ) thesis depends: "Mind and consciousness are not unique features of human brains. They are grounded in inherent features present in simpler forms in virtually every species. Any organism with flexible cell walls, a sensitivity to its surrounds and the capacity for locomotion will possess the biological foundations of mind and consciousness" (p. 4).

Note that although Reber's analysis of the distribution of consciousness is far more inclusive than most, it is still a discontinuity theory that separates organisms that possess a form of consciousness from those that don't, placing the boundary between single cells that are responsive to their environment and have a capacity for locomotion and those that don't. For example, he excludes "plants and fungi on the grounds that they have rigid cell walls composed of cellulose, hemicellulose and pectin (plants) or chitin (fungi), and lack the capacity for endogenous locomotion" (p. 4, note 4).

One could of course point out that some plants are responsive to their environment and have the ability to move. For example, the leaflets of the Mimosa plant habituate to repeated stimulation - i.e., the leaflets rapidly close when first touched - but after repeated stimulation they re-open fully and do not close again while the stimulus remains the same. Surprisingly, this habituation is stimulus-specific. For example, Holmes \& Yost (1966) induced leaflet closure using either water droplets or brush strokes, and after repeated stimulation (with either stimulus) habituation occurred. But if the stimulus was changed (from water drops to brush strokes or vice-versa), leaflet closure re-occurred (see also Applewhite, 1975, for a review).

Whether or not one might wish to include some plants, these demarcation criteria still present a mystery: why should having flexible cell walls and endogenous motility provide a clear separation between it being "like something to be something" and being like nothing at all? In principle, for example, it might be like something to have inflexible cell walls and little movement. Or to express the mystery the other way around, what is it about having flexible cell walls or endogenous motility that suddenly switches on consciousness?

Reber admits to the problem. In his critique of the many theories that about brain-based consciousness he points out that they:

“... all suffer a fatal flaw: they require a miracle. They all need to specify the properties of complex neural states that give rise to conscious states; they have to identify the neural or computational properties that permit a brain to make a mind. And worse, they need to explicate why, when a neurological system crosses some threshold of complexity or hits upon the right set of interconnecting neural centers and pathways, it suddenly 'makes consciousness.' ... Admittedly, the CBC also calls for a miracle, but it's a very small one and far more tractable than the ones that current neuroscientists and philosophers of mind have put on the table for us." (p. 7)

But miracles that take place in little cells are still miracles! In my view, Reber's assertion that these are far more tractable than miracles in big brains, along with his subsequent argument, confound the conditions for the existence of consciousness (of any kind) with the added conditions required to determine the many forms it can take (Velmans, 2012). Why does Reber's "small miracle" of cellular consciousness and his subsequent analysis of its 
evolution seem to make the existence of human consciousness more tractable? Because once one assumes the existence of consciousness (in a single cell) - together with an as yet undiscovered but entirely plausible relationship between different forms of mental functioning and the forms of phenomenal consciousness that accompany them - one can give an entirely functional account of how adaptive mental functions and their accompanying experiences co-evolve (Velmans, 2012). Who can doubt that verbal thoughts require language, or that full human self-consciousness requires a theory of mind? Without internal representations of the world, how could consciousness be of anything? And without motility and the ability to approach or avoid, what point would there be to rudimentary pleasure or pain? However, none of these theories explains what it is about such biological functions that suddenly switches on consciousness (Velmans, 2011)

There is much more to be said about these fundamental problems and how one might resolve them. Commentary length restrictions in Animal Sentience do not allow elaborating them here. A fuller version of this commentary, with a more elaborate analysis of Reber's $\mathrm{CBC}$ theory along with an alternative, continuity approach can be found here.

\section{References}

Applewhite, P. B. (1975). Learning in bacteria, fungi, and plants. In: W. C. Corning, J. A. Dyal, and A.O. D. Willows (Eds.), Invertebrate Learning, Vol.3: Cephalopods and Echinoderms. New York and London: Plenum Press.

Holmes, E. and Yost, M. (1966). Behavioral studies in the sensitive plant. Worm Runners Digest, 8, 38.

Reber, A. (2016). Caterpillars, consciousness and the origins of mind. Animal Sentience 2016.106.

Velmans, M. (2000). Understanding Consciousness. London: Routledge/ Psychology Press.

Velmans, M. (2007). The co-evolution of matter and consciousness. Synthesis Philosophica, $44(2), 273-282$.

Velmans, M. (2009) Understanding Consciousness, Second Edition. London: Routledge/Psychology Press.

Velmans, M. (2011). Can evolutionary theory explain the existence of consciousness? A review of Humphrey, N. (2010) Soul Dust: The Magic of Consciousness. London: Quercus. Journal of Consciousness Studies, 18(11-12), 243-254.

Velmans, M. (2012). The evolution of consciousness. In D. Canter and D. Tunbull (Eds.), Contemporary Social Science. Special Issue on Biologising the Social Sciences: Challenging Darwinian and Neuroscience Explanations, 7(2), 117-138. 